\title{
Lasting effects of general anesthetics on the brain in the young and elderly: "mixed picture" of neurotoxicity, neuroprotection and cognitive impairment
}

\author{
Lingzhi Wu ${ }^{1} \cdot$ Hailin Zhao ${ }^{1} \cdot \mathrm{Hao} \mathrm{Weng}^{2} \cdot$ Daqing Ma $^{1}$ (1)
}

Received: 4 September 2018 / Accepted: 4 February 2019 / Published online: 11 March 2019

(c) The Author(s) 2019

\begin{abstract}
General anesthetics are commonly used in major surgery. To achieve the depth of anesthesia for surgery, patients are being subjected to a variety of general anesthetics, alone or in combination. It has been long held an illusory concept that the general anesthesia is entirely reversible and that the central nervous system is returned to its pristine state once the anesthetic agent is eliminated from the active site. However, studies indicate that perturbation of the normal functioning of these targets may result in long-lasting desirable or undesirable effects. This review focuses on the impact of general anesthetic exposure to the brain and summarizes the molecular and cellular mechanisms by which general anesthetics may induce long-lasting undesirable effects when exposed at the developing stage of the brain. The vulnerability of aging brain to general anesthetics, specifically in the context of cognitive disorders and Alzheimer's disease pathogeneses are also discussed. Moreover, we will review emerging evidence regarding the neuroprotective property of xenon and anesthetic adjuvant dexmedetomidine in the immature and mature brains. In conclusion, "mixed picture" effects of general anesthetics should be well acknowledged and should be implemented into daily clinical practice for better patient outcome.
\end{abstract}

Keywords General anesthetics $\cdot$ Brain $\cdot$ Neurotoxicity $\cdot$ Neuroprotection

\section{Introduction}

Modern anesthesia enabled increasingly complicated surgical and diagnostic procedures to be performed safely on patients, and has significantly advanced human medicine. For years after its advent, it was believed that general anesthetics (GAs) exert reversible, temporary effect on the central nervous system, which would return to its pristine state once the anesthetic exposure is ceased. The long-lasting effects including cellular signaling changes and their impact after anesthetic exposure are enormous [1]. These

Daqing Ma

d.ma@imperial.ac.uk

1 Anaesthetics, Pain Medicine and Intensive Care, Department of Surgery and Cancer, Faculty of Medicine, Imperial College London, Chelsea and Westminster Hospital, London, UK

2 Department of Anesthesiology, Shanghai Fengxian District Central Hospital, Shanghai Jiao Tong University Affiliated Sixth People's Hospital South Campus, Fengxian District, Shanghai, China effects can be desirable or undesirable. Indeed, anesthetics received during surgery were shown to be associated with brain dysfunction in young and elderly [2, 3]. In years to come, a large body of pre-clinical studies, and accumulating clinical evidences has steadily strengthened the belief that anesthetics may produce morphological changes and longterm functional impairment in brains at the extremes of age. Amidst the growing evidences linking GAs to neurocognitive impairment, the United States Food and Drug Administration issued a precautionary communication on GA use in patients aged three years and under [4], accentuating GArelated public health concerns. In this review, we attempt to provide a comprehensive discussion on the unwanted effects of general anesthetics on the central nervous system (CNS), integrating pre-clinical findings with clinical evidences.

Mechanism studies revealed that GAs act through various receptor proteins to modulate neuronal activities, to exert their amnesic, analgesic, sedative and immobilizing effects. The most recognized receptor targets include $\mathrm{GABA}_{\mathrm{A}}$ receptor (propofol, etomidate, isoflurane, sevoflurane), NMDA receptor (nitrous oxide, xenon, ketamine), glycine receptor and two-pore potassium channel $[5,6]$. Such inhibitory and 
activating receptors are abundant throughout the mammalian brain, and may mediate unwanted, off-target effect of GAs to precipitate long-term cognitive dysfunction. In this regard, the extraordinary plasticity/connectivity and reduced compensating capacity of the developing and aging brains, respectively, may make them vulnerable to the ubiquitous, undesired actions of general anesthetics.

\section{The developing brain}

\section{General anesthetics and neurotoxicity}

Over the years, cellular and animal studies yielded substantial and convincing evidence on the cytotoxic and neurotoxic properties of general anesthetics. Since the pioneering study by Jevtovic-Todorovic et al., whereby $6 \mathrm{~h}$ exposure to a mixture of nitrous oxide, isoflurane and midazolam in postnatal day 7 rats induced long-term learning deficits [7], studies have demonstrated that routine GAs (isoflurane [8, 9], sevoflurane, propofol [10, 11], ketamine [12]) are capable of producing lasting cognitive, behavioral and memory deficiency in rodents when exposed in the early postnatal period. Studies on non-human primates mirrored such findings, wherein early-life exposure to ketamine, sevoflurane or isoflurane led to persistent decline in cognitive, executive, memory and motivation-based tasks, and increased anxiety behaviors in the long term [13-15]. Based on the cumulative findings, the potency of GAs on neurobehavioral development is likely determined by the total length of exposure (a single lengthy vs. repeated brief exposures) and the developmental stage of the animal (first week postnatal). It was also reported that age of the neuron per se better predicts vulnerability to GAs than age of the organism, wherein juvenile neurons in adult animals are susceptible to the effect of GAs [16], to suggest neurocognitive toxicity of GAs even in adulthood.

The molecular mechanisms underlying GA's lethality in developing neurons have been extensively explored. In vitro studies consistently reported the role of mitochondria and intrinsic (mitochondrial) apoptosis in GA-induced neurotoxicity. In neuronal culture and brain slice derived from immature rodents, isoflurane exposure significantly decreased anti-apoptotic BCL-2/pro-apoptotic Bax ratio, increased reactive oxygen species (ROS), and promoted cytochrome $\mathrm{C}$ release from mitochondria and caspase 3 cleavage [17-19]. Subsequent studies identified inositol 1,4,5-trisphosphate receptor (InsP3R) located on endoplasmic reticulum (ER) as a novel target of GA and an upstream signaling component of mitochondria. Under physiological conditions, activation of the InsP3R leads to $\mathrm{Ca}^{2+}$ release from ER lumen into the cytosol to initiate calcium-dependent signaling. Isoflurane was shown to directly open InsP3R channels to induce excessive $\mathrm{Ca}^{2+}$ release from ER into cytosol and mitochondria, which further leads to mitochondrial calcium overload, ATP production failure, cytochrome $\mathrm{C}$ release and caspase activation [20-22]. In addition to targeting the mitochondria, recent data suggests that GA-induced cytosolic calcium buildup also impairs autophagosomal and autolysosome function to reduce cytoprotective autophagy, which would bias cell towards apoptosis [23] (Fig. 1).

Retrospective cohort studies found that multiple rounds of anesthetic exposure, and in young children under $2-4$ years of age, were associated with learning difficulty and academic underachievement during childhood and adolescence [24, 25]. Single, brief anesthetics exposure, on the other hand, in pediatric patients younger than 3 years of age, was not found to be associated with neurocognitive or behavioral impairment [26]. However, one study reported that both single and multiple exposures to anesthesia were linked to language and abstract reasoning deficits [27]. The discrepancy is likely due to the selection bias inherent to retrospective study design, different assessment parameters, and/or age at assessment. Two prospective clinical studies examined the effect of single general anesthetic exposure at young age on future neurocognitive performance. The General Anesthesia compared to Spinal anesthesia (GAS) trial showed that GA is not associated with cognitive impairment compared to awake SA at 2 years of age [28]. The Pediatric Anesthesia Neurodevelopment Assessment (PANDA) trial also did not observe significant decline in cognitive, behavioral and memory capacity in GA-exposed subjects in comparison to their unexposed siblings, at 8-15 years of age [29]. Nevertheless, such findings cannot rule out the possibility that longer duration, repeated anesthetic exposure can harm the developing brain.

These studies are present with various confounding factors that warrant cautious interpretation of results. As anesthetics are rarely given alone, these studies rather assessed the association between surgery plus anesthetic exposure and cognitive/behavioral deficiency, instead the risks associated with anesthetics per se [30,31]. In this regard, it would be difficult to dissect out the effect of surgery on neurocognitive development; moreover, children requiring surgery at young age are known to be different in many ways from those who do not, and such developmental differences may contribute to neurocognitive deficit attributed to surgery and/or anesthesia. Furthermore, confounders such as hypotension, body temperature, and hypoxia during surgery are rarely described/controlled for in these studies, and could potentially alter the outcomes. In view of such, it would be very difficult to establish whether general anesthetics are causally linked to cognitive and behavioral deficiency, or conditions associated with such. Thus, large-scale observational studies and randomized trials with longer duration exposure of GAs and follow-up, more sensitive outcome measures, and 


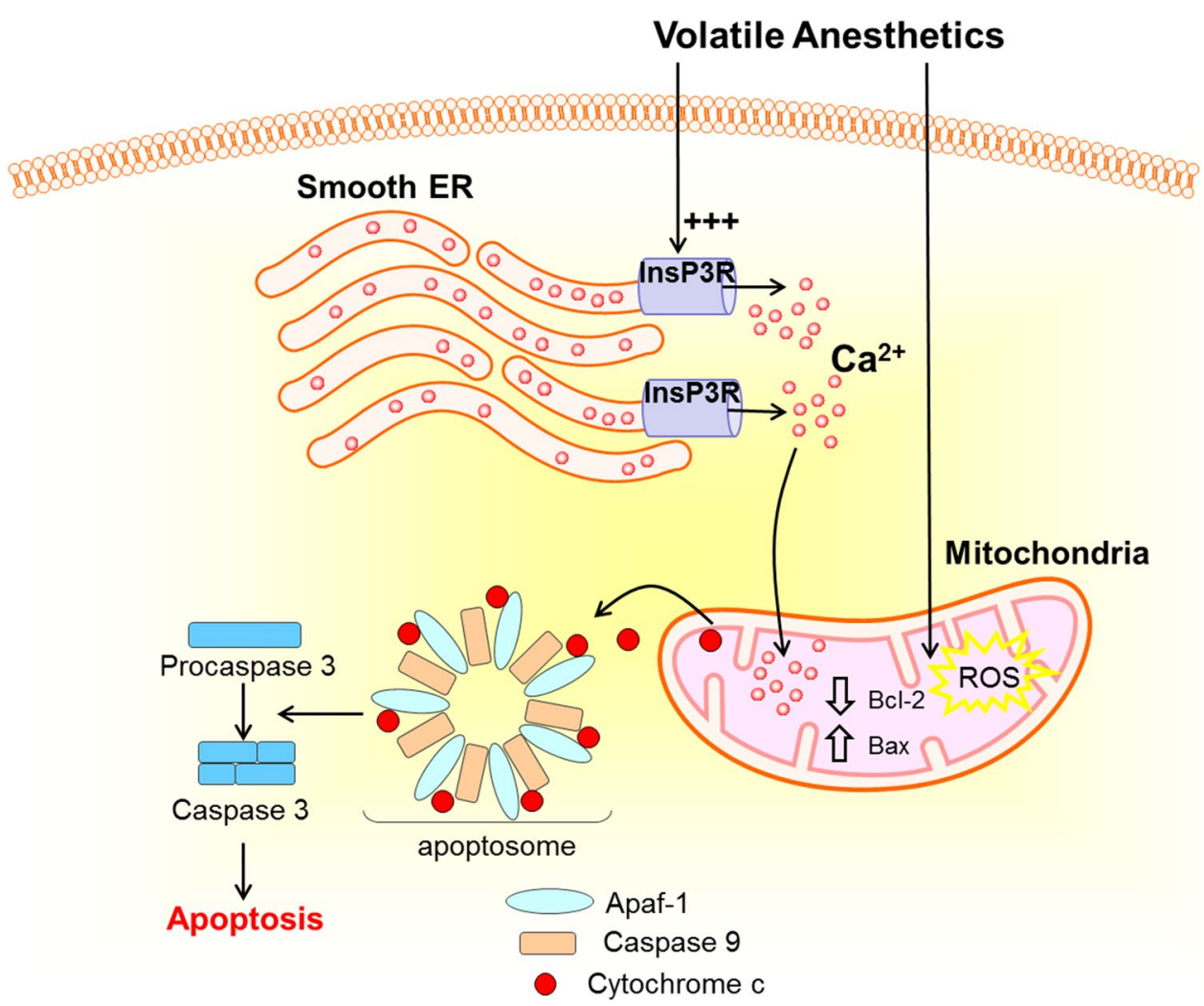

Fig. 1 Neurotoxicity and volatile anesthetics. Volatile anesthetics were shown to activate mitochondrial apoptosis pathway, by increasing mitochondrial ROS production, lowering anti-apoptotic Bcl-2/ pro-apoptotic Bax ratio and promoting cytochrome $\mathrm{C}$ from mitochondrion into cytosol to form apoptosome, which subsequently cleaves pro-caspase 3 to caspase 3 . In addition, volatile anesthetic isoflurane was demonstrated to directly activate and open inositol 1,4,5-trisphosphate receptor (InsP3R) calcium channel located on

stringent confounder control are required in the future, to provide more conclusive and informative data.

\section{Neuroprotection in hypoxic-ischemic brain injury}

Cerebral hypoxic brain injury contributes significantly to perinatal mortality and morbidity worldwide. It affects approximately 4 in 1000 births [32] and causes permanent neurological deficits in $25 \%$ of sufferers [33]. It is estimated that 4 million babies die in the neonatal period every year and birth asphyxia accounts for $23 \%$ of these deaths [34]. The lifelong consequences of perinatal hypoxic-ischemic encephalopathy to the affected infants, their family and the society necessitate the development of novel neuroprotective strategies. Hypoxic brain injury develops when oxygenation of the brain tissue is reduced, usually due to cardiac arrest or cerebrovascular incidents [35]. In the adult brain, this mostly occurs in the form of stroke. In infants, the most common type of hypoxic brain injury is due to ischemia superimposed on hypoxia [33]. During or after birth, reduction in cerebral the smooth endoplasmic reticulum. Excessive opening of InsP3R calcium channel by isoflurane leads to significant $\mathrm{Ca} 2+$ leakage from ER and cause mitochondrial $\mathrm{Ca} 2+$ overload, which could aggravate cytochrome $\mathrm{C}$ release and caspase cleavage pathway. Apaf- 1 Apoptotic protease-activating factor $1, \operatorname{Bax} \mathrm{Bcl}-2$-associated $\mathrm{X}$ protein, $B c l-2$ B-cell lymphoma 2 protein, $\mathrm{Ca}^{2+}$ calcium ion, InsP3R inositol 1,4,5-triphosphate receptor, $R O S$ reactive oxygen species

blood flow or further deoxygenation of the blood leads to the pathological asphyxia. The leading cause of hypoxic brain injury in the newborn is placental blood flow abruption and impaired gas exchange [36]. The brain injury is diffuse not focal, and affects the whole brain homogeneously [33]. During hypoxia/ischemia brain injury, energy depletion is due to the hypoxemia that switches cellular metabolism from aerobic to anaerobic. Anaerobic metabolism is insufficient to meet the cellular energy demands, which lead to depletion of stored ATP, creatinine phosphate and other forms of energy [37, 38]. Basic cellular proteins such as the $\mathrm{Na}^{+} /$ $\mathrm{K}^{+}$-ATPase no longer function properly, leading to $\mathrm{Na}^{+}$and $\mathrm{Ca}^{2+}$ influx, followed by cytotoxic edema and lysis [38, 39]. The brain tissue of the affected areas has a biphasic response to a hypoxic-ischemic injury [40, 41]. First, there is primary cell death, which includes the death of affected cells via necrosis during or shortly after the hypoxia, then secondary cell death via apoptosis $8-72 \mathrm{~h}$ after the hypoxia [42] or through autophagosomal or lysosomal death [43]. 
Glutamate neurotoxicity, or excitotoxicity, is the overstimulation of neuronal cells by glutamate that is released due to the depolarized membrane, and is a central feature to hypoxic-ischemic brain injury. Ischemic insult causes significant release of glutamate from excitatory nerve terminals, to promote water influx via the opening of surface channels such as the AMPA receptors and further influx of $\mathrm{Ca}^{2+}$ through the NMDA receptors on post-synaptic neuron membrane [44]. Accumulation of cytosolic $\mathrm{Ca}^{2+}$ leads to free radical production through formation of xanthenes and prostaglandins, cell membrane damage, phospholipase C activation, activation of endonucleases as well as apoptosis proteins, ultimately leading to cell death [45].

Much work has focused on the excitotoxicity-antagonizing effect of general anesthetic. Early studies reported that isoflurane directly interacts with the glutamatergic N-Methyl-D-aspartic acid (NMDA) receptor, whereby isoflurane may suppress NMDA or $\alpha$-amino-3-hydroxyl5-methyl-4-isoxazole-propionate (AMPA)-induced glutamate release, calcium uptake, mitochondrial membrane depolarization and excitatory neurotransmission [46-48]. Inhalational anesthetics sevoflurane and halothane were also shown to inhibit NMDA-induced excitotoxicity and calcium transient, however, the extent of neuroprotection appears to be lesser than that of isoflurane [48]. In this regard, excitotoxicity antagonism has been regarded as one of the mechanisms inhalational anesthetics act through to protect against ischemic brain injury. In addition, isoflurane interacts with and agonize inhibitory gamma-Aminobutyric acid-A (GABA) receptor that would inhibit depolarization and excitatory neurotransmission $[49,50]$ (Fig. 2).

Similar to that of volatile anesthetics isoflurane and nitrous oxide, xenon inhibits the plasma membrane $\mathrm{Ca}^{2+}$ pump, which might be responsible for neuronal $\mathrm{Ca}^{2+}$ concentration increase and altered excitability [51]. In 1998, it was shown that xenon suppresses nociceptive responsiveness through inhibition of NMDA receptors [52]. Xenon is different from all other volatile anesthetic agents, as it exerts no action on $\mathrm{GABA}_{\mathrm{A}}$ receptors [53]. It was predicted through biochemical modeling that xenon binds at the glycine site of the NMDA receptor and causes potent non-competitive inhibition [54]. Compared with commonly used anesthetic agents, xenon-induced anesthesia is featured with greater circulatory stability, lower analgesic consumption, lower adrenergic levels and better perfusion of individual organs [55]. Furthermore, xenon's anesthetic effect is 1.5 times greater than that of nitrous oxide [56]. Nowadays, xenon has been used in anesthesia for many different types of surgery [57, 58].

Following the discovery that xenon is capable of inhibiting NMDA receptors, it was naturally postulated that xenon can protect neuronal cell against injury, since NMDA receptor-mediated neurotoxicity plays a critical role in neuronal cells death. Ma et al. [59] demonstrated the neuroprotective effect of xenon through N-methyl (D, L)-aspartate-induced neurotoxicity. Later, $\mathrm{Ma}$ et al. [60] demonstrated that xenon preconditioning improved both morphology and neurological functional outcome after the hypoxia-ischemia insults. The mechanism of xenon preconditioning may be due to increased synthesis of survival proteins such as Bcl-2.The effect of xenon-mediated organoprotection was investigated in combination with methods in general clinical practice. Ma et al. [61] demonstrated that combination of xenon and hypothermia caused a synergistic enhancement of their individual neuroprotective properties. In addition to preconditioning, there are also studies demonstrating the effectiveness of post-treatment of xenon in brain injury. Dingley et al. [62] showed that xenon administered after a hypoxic-ischemic insult in neonatal rat model conferred uniformly $80 \%$ neuroprotection, as assessed by neuropathology of the major areas of the brain. The neuroprotective effect of xenon was further tested on large animals. Schmidt et al. [63] evaluated whether xenon provides a neuroprotective effect to attenuate brain injury after transient cerebral ischaemia due to cardiac arrest in pigs. The major findings were that during reperfusion, brain injury is significantly smaller with the xenon treatment than control. Faulkner et al. [64] compared the effect of hypothermia and xenon-augmented hypothermia on the brain after transient global hypoxia-ischemia in piglet, whereby combination with xenon further reduced levels of cell death and tissue damage. In 2010, xenon exposure combined with hypothermia was conducted for the first time on a newborn baby suffering from hypoxia at birth. The treatment was demonstrated to be very effective in attenuating mild brain injury in the young [65].

Hypoxia-inducible factor-1 (HIF-1) is the central mediator of the cellular response to hypoxic environments, and represents a key mechanism that inhalational anesthetics act upon to provide neuroprotection against ischaemic brain injury [66]. HIF-1 is a transcription factor belonging to the basic helix-loop-helix-Per-Arnt-Sim (bHLH-PAS) family. It is a heterodimer composed of $\alpha$ and $\beta$ subunits; $\alpha$ subunit is continuously made and degraded in both normoxic and hypoxic conditions, whilst $\beta$ subunit is insensitive to oxygen [67]. HIF-1 mutations are known to lead to neural tube defects, brain underdevelopment and decreased neuronal cell number [68]. HIF-1 can be activated during hypoxia due to accumulation of the $\alpha$ subunit through reduced degradation [67]. The degradation of the HIF- $1 \alpha$ subunit is mediated through the Von Hippel-Lindau (VHL) tumor-suppressor protein. VHL interacts with Elongin $\mathrm{C}$ and ubiquitinates HIF- $1 \alpha$, targeting it for proteosomal degradation [67]. HIF-1 hydroxylation is promoted by propyl hydroxylase (PHD), which is oxygen dependant [69]. Growth factors such as insulin-like growth factor (IGF)-1 and FGF bind to their receptors and activate the 


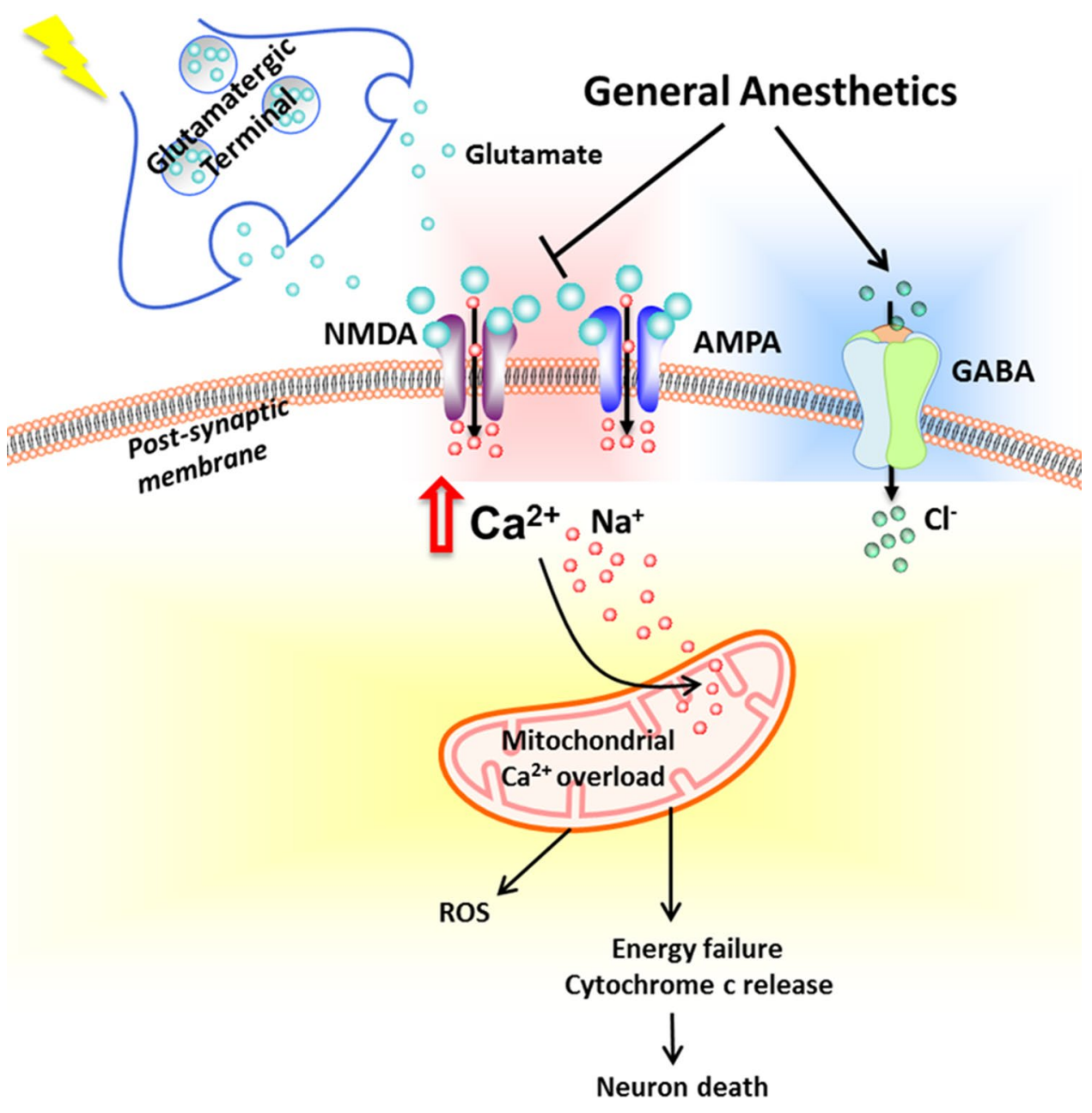

Fig. 2 Excitotoxicity and general anesthetics. Glutamate released from pre-synaptic nerve terminals bind to NMDA and AMPA receptors on the post-synaptic membrane to lead to calcium ion $\left(\mathrm{Ca}^{2+}\right)$ influx and membrane depolarization. Excessive glutamatergic signaling and calcium accumulation would result in mitochondrial calcium overload, reactive oxygen species (ROS) production, cellular energy failure, apoptosis protein (cytochrome C) release/activation, and ultimately neuron death. Activation of GABA receptor leads to chloride ion $\left(\mathrm{Cl}^{-}\right)$influx to hyperpolarize membrane and thus inhib-

PI3 kinase/Akt/mTOR pathway, initiating HIF-1 $\alpha$ production [70]. The critical gene expression after HIF activation mediates cellular responses to the hypoxia, including enhanced cell survival, erythropoiesis and angiogenesis [68] (Fig. 3). In this regard, volatile anesthetic halothane was shown to inhibit hypoxia-induced activation of HIF-1 [71], whereas isoflurane and xenon were demonstrated to upregulate HIF- $1 \alpha$ expression and activity to confer kidney protection against ischemic insult [72-75]. Similarly, neuroprotection by isoflurane and xenon in ischemic brain injury is accompanied by HIF-1a upregulation [76, 77], which likely owes to volatile anesthetics' ability to activate PI3K/AKT and ERK1/2 phosphorylation pathways. its depolarization. Volatile anesthetics (in particular isoflurane) have been shown to antagonize NMDA and AMPA, inhibit $\mathrm{Ca}^{2+}$ influx and protect neuron death from ischemia-induced excitotoxicity. Isoflurane also agonizes GABA receptor to hinder excitatory neurotransmission. $A M P A$ a-amino-3-hydroxyl-5-methyl-4-isoxazole-propionate, $\mathrm{Ca}^{2+}$ calcium ion, $\mathrm{Cl}^{-}$chloride ion, $\mathrm{GABA}$ gamma-aminobutyric acid-A, $\mathrm{Na}^{+}$sodium ion, $N M D A N$-Methyl-D-aspartic acid, $R O S$ reactive oxygen species

\section{Elderly and cognition}

\section{Cognitive disorders}

Cognitive disturbance is commonly observed in elderly patients following surgery and general anesthesia and is predictive of short- and long-term outcomes. Cognitive disorders include postoperative delirium (POD) and postoperative cognitive dysfunction (POCD). Unlike POD, as of current, accurate diagnosis of POCD is made difficult by the lack of formal, universal diagnosis criteria and the varying degree/extent of symptom presentation. POD is an 


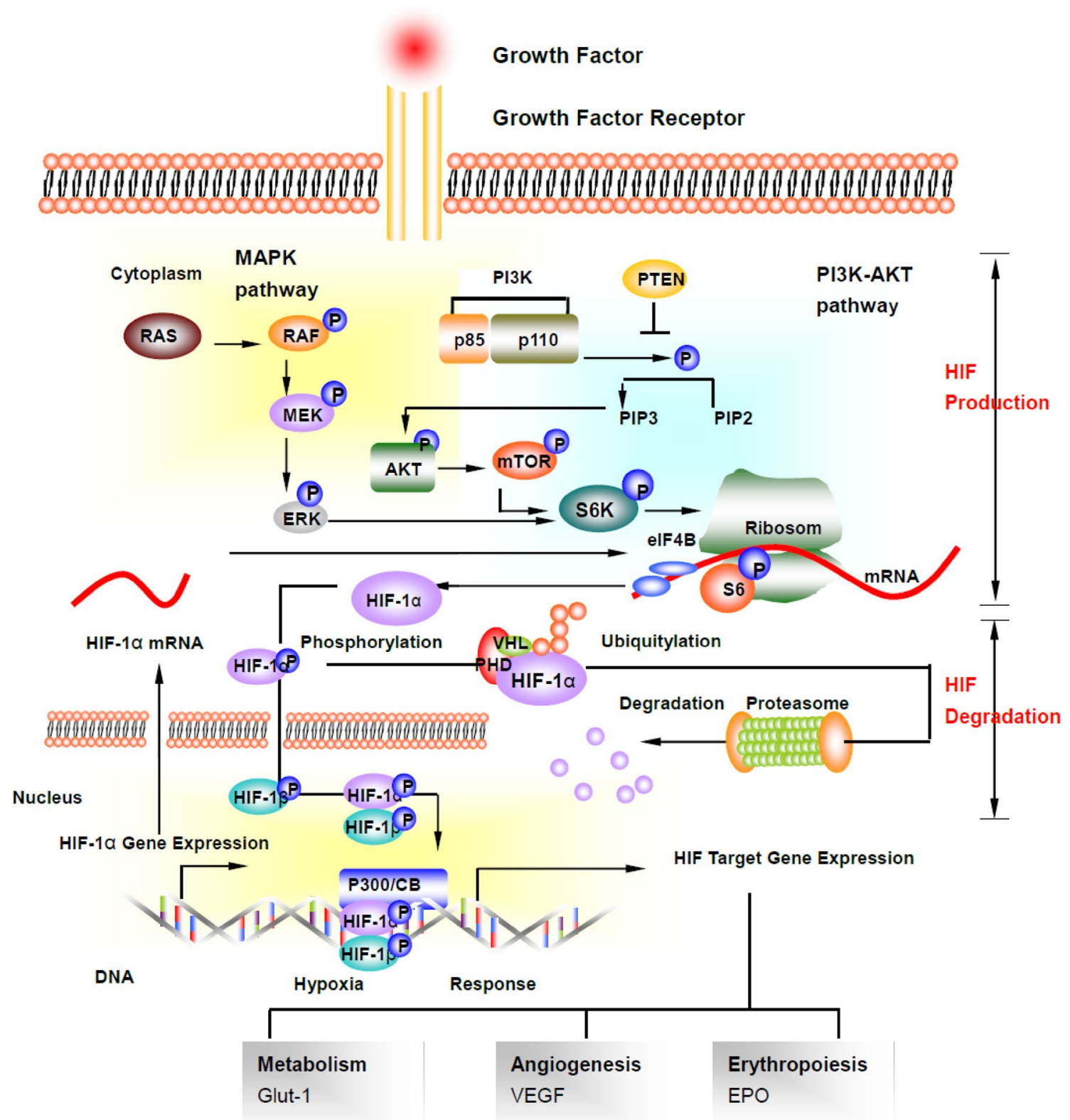

Fig. 3 The hypoxia-inducible factor-1 (HIF-1) signaling pathway. Volatile anesthetics has been shown to activate or suppress HIF-1 system. HIF-1 is a heterodimer that consists of HIF-1 $\alpha(120 \mathrm{kDa})$ and HIF-1 $\beta$ (91-94 kDa), HIF1 $\beta$ is expressed constitutively in all cells and remains stable regardless of oxygen tension. At normoxia conditions, HIF- $1 \alpha$ combines with the tumor-suppressor Von Hippel-Lindau (VHL) protein through a hydroxylated proline residue and is then hydroxylated by prolyl-4-hydroxylases (PHD) in the cytoplasm, and this interaction causes HIF-1 $\alpha$ to be ubiquitinated and to be targeted by proteasome-mediated protein degradation. Under hypoxic conditions, oxygen deficiency inhibits the activity of prolyl hydroxylases

acute and transient disturbance that affects early postoperative period (days to weeks), whereas POCD manifests as more subtle deteriorations in memory, attention, and cognition over a much longer period of time (months to and leads to the accumulation of HIF- $1 \alpha$. Production of HIF- $1 \alpha$ is controlled by PI-3K/AKT/mTOR pathway and partially influenced by MAPK pathway, phophorylation of AKT and mTOR leads to translation of HIF-1 $\alpha$. HIF- $1 \alpha$ is translocated into the cell nuclear and together with HIF-1 $\beta$ bind to hypoxia-response elements (HREs). A broad range of protective pathways is activated, which regulate several aspects of cellular activities, such as angiogenesis, erythropoiesis, cell proliferation, cell survival and energy metabolism. AKT protein kinase $\mathrm{B}, H I F-1$ hypoxia-inducible factor-1, MAPK mitogenactivated protein kinase, $m T O R$ mammalian target of rapamycin, $P I$ $3 K$ phosphatidylinositide 3-kinases

years). The observed incidence of POD ranges from 10 to $45 \%$ that increases with age and surgery complexity/ risk [78], and POCD was reported to affect $26 \%$ patients over 60 years in the first postoperative week, and the 
incidence falls to $10 \%$ in the following 3 months [79]. However, clinical evidence attributing POCD to surgery and anesthesia exposure are inconclusive [80], as longterm follow-up study found only $1 \%$ of elderly subjects suffer from persistent POCD 1-2 years onwards [81], with pre-operative cognitive performance (e.g., mild cognitive decline, possible/probable Alzheimer's disease) being a better predictor of postoperative cognitive trajectory [82]. The general consensus now is that POCD is multi-factorial with various biological and socioeconomic predisposing factors. Despite the debatable cause of POCD syndromes, it remains a perioperative priority that demands all plausible factors to be considered for lowering its incidence. Amongst the many predisposing factors, the choice of anesthetic agent/technique represents a likely one [83, 84].

Clinical studies investigating the potential role of anesthetics in POCD have been inconclusive. When compared with regional anesthesia, general anesthesia was not found to be associated with significantly higher incidence of delirium and POCD in elderly patients 3 months following surgery $[85,86]$. In another study, incidence of POCD in the first postoperative week was shown to be independent of the mode of anesthesia (light sedation, intravenous or inhalational) and the type of surgery [87]. In two studies that examined the effect of anesthesia depth (as determined by BIS index) on cognitive function in elderly, one found that deep anesthesia $($ BIS $<20)$ was associated with higher incidence of delirium but not POCD [88], whereas the other showed that light anesthesia (BIS 55-70) impaired information processing ability 4-6 weeks after surgery [89]. Moreover, a case-control study examining later life POCD risk reported that GA exposure after age of 40 was not associated with increased rate of mild cognitive impairment in subjects of 70-89 years of age [90]. A randomized trial reported that sevoflurane was associated with better postoperative cognitive function than propofol-based anesthesia following on-pump cardiac surgery, and it was suggested that sevoflurane could compensate for the cognitive consequences from intraoperative cerebral desaturation [91]. In these clinical scenarios, it should be noted that the effect of surgery or any co-morbidities is likely to be more prominent and could have masked the subtle influences of anesthesia on cognitive performance. Clinical observations could be further confounded by the lack of reliable diagnostic criteria and timing for POCD, as mentioned above.

A large number of animal studies have been conducted to examine the deleterious effect of general anesthesia in the absence of surgical insults. Volatile anesthetics isoflurane [92] and desflurane [93] were found to induce longterm impairment in spatial memory acquisition and learning in 18- to 20-month-old rats, when assessed by radial arm maze. Such findings were challenged by another study that demonstrated isoflurane exposure did not impair spatial memory and learning (Morris Water Maze) in aged rats, which corresponded to isoflurane's lack of effect on neurogenesis and cell death within the hippocampus [94]. Other general anesthetics were also reported to lack detrimental effects. Sevoflurane did not impair acquisition learning and memory in 20- to 24-month-old rats and may even improve long-term learning capacity [95]. Similarly, long-term spatial memory and learning was also preserved in 18-monthold rats receiving intravenous propofol [96]. The collective findings suggest that GA choice could differentially affect long-term cognitive outcome, with certain anesthetics being more favorable in susceptible elderly patients. To answer such questions, studies comparing the cognitive effects of different anesthetics at equipotent doses and of comparable exposure durations would be required. A recent clinical study indicated that in comparison with sevoflurane, propofol-based general anesthesia decreased the incidence of delayed neurocognitive recovery, a derivative form of POCD, in older adults after major cancer surgery [97].

In the search of prophylaxis and therapy against POD, the anesthetic adjuvant dexmedetomidine has been shortlisted as a promising candidate. As an alpha ${ }_{2}$-adrenergic receptor agonist, it is hypothesized that dexmedetomidine interacts with different physiological and biochemical pathways within the CNS to achieve multitude anti-delirium neuroprotection. Dexmedetomidine binds to $\mathrm{a}_{2}$ adrenoceptors in locus ceruleus (LC) to inhibit neuronal activity within LC, which subsequently leads to release of inhibitory neurotransmitters GABA and galanin into the cortex to promote natural sleep-like sedation [98, 99]. Moreover, dexmedetomidine also reduces the requirement of benzodiazepines and opioids throughout the perioperative period, and this could thus reduce delirium occurrence due to benzodiazepine/ opioid use. Using animal models of surgical trauma and/or anesthesia exposure, it has been demonstrated that Dex has anti-apoptosis [100] and anti-inflammatory [101] properties that is associated with improved neurocognitive outcome. We proceeded to test the delirium-attenuating potential of dexmedetomidine in a prospective randomized trial, which enrolled 700 elderly patients to receive low-dose dexmedetomidine or saline for overnight hours in ICU after non-cardiac surgery. The trial demonstrated that low-dose, prophylactic dexmedetomidine in patients $>65$ years of age significantly reduced the incidence of postoperative delirium in the first week after surgery [102]. In the 3-year follow-up study of the trial, we further demonstrated that dexmedetomidine recipients showed significantly improved quality of life, cognitive function and long-term survival [103]. In a parallel, in a separate randomized trial study, we demonstrated that prophylactic dexmedetomidine in non-cardiac surgery patients increased non-rapid eye movement sleep and improved overall sleep quality, which likely contribute to the lowered incidence of delirium [104]. In an independent study, as 
opposed to prolonged infusion, Deiner et al. showed that dexmedetomidine administration at a relative high dose during the intraoperative period and 2 subsequent hours in non-cardiac surgery patients did not significantly reduce the occurrence of delirium in the first perioperative week and cognitive dysfunction at 3-6 months after surgery [105]. The collective findings highlight the short-acting nature of dexmedetomidine, and the need for continuous infusion and specific timing when using dexmedetomidine for delirium and POCD prevention and may be also patient population specific.

\section{Alzheimer's disease}

A number of pre-clinical studies on transgenic animals carrying $\mathrm{AD}$-predisposing genetic alterations have examined the molecular, morphological and behavioral outcomes following exposure to general anesthetics. In these studies, the transgenic animals harbor one or more genetic mutations of the amyloid protein cascade, including mutation to amyloid precursor protein (APP) and/or proteolytic enzyme that cleaves APP (e.g., $\gamma$-secretase-presenilin 1 or presenilin 2 mutation), which leads to excessive production of neurotoxic A $\beta 42$ fragment and deposition of amyloid plaques. Additional mutation to tau protein can also be introduced to generate tri-transgenic animals that exhibit hyper-phosphorylated tau and neurofibrillary tangles (NFT), which better recapitulate the broad spectrum of $\mathrm{AD}$ pathology in human [106].

An early study demonstrated that intermittent isoflurane or halothane exposure for 5 days impaired cognitive function in 12-month-old wildtype but not Tg2576 transgenic mice (overexpressing mutant human APP), with halothane exposure significantly increasing amyloid deposition in $\mathrm{Tg} 2576$ subjects [107]. A plausible explanation could be that $\operatorname{Tg} 2576$ mice already exhibit significantly lower baseline cognition that does not deteriorate further upon anesthetic challenge, unlike wildtype animals. Another group found that repeated, prolonged isoflurane exposure over a course of 3 months hindered Y-maze ambulatory behavior in transgenic Tg2576 mice; isoflurane elevated $\mathrm{A} \beta_{1-42}$ amyloid deposition not only in transgenic animals but also in wildtype counterparts, despite such effects being more prominent in the transgenic group [108]. Thus, with the same genetic background, the neurotoxic effect of inhalational anesthetics is duration dependent and specific to different test paradigms, and a certain threshold of molecular alternation must be exceeded to produce noticeable cognitive regression. In APP695 mice that displays significant amyloidopathy in the hippocampus, $4 \mathrm{~h}$ exposure to $1 \mathrm{MAC}$ isoflurane significantly impaired spatial memory performance as assessed by Morris Water Maze [109], with the effects being more subtle in wildtype animals. In an attempt to study the combined effect of anesthesia plus surgery, $2 \mathrm{~h}$ exposure to isoflurane, but not desflurane, with brief laparoscopy significantly increased escape latency in Barne maze test in 5-month 5XFAD mice (transgenic with five familial Alzheimer's disease mutations, amyloid deposition and intraneuronal $A \beta_{42}$ accumulation are evident at only 2 months of age), indicating worsened cognitive function [110]. The same group further reported that sevoflurane with brief laparoscopy reduced freezing time of fear conditioning system in only female but not male 5XFAD mice, to suggest sex-dependent impairment to hippocampus-mediated cognitive function [111]. In other AD mouse models, the detrimental effect of inhalational anesthetics on cognition is less conclusive. Contrary to the previous neurotoxic findings, one study reported that $2 \mathrm{~h}$ of 1MAC isoflurane exposure significantly improved learning and cognition in 4-month-old APP23 mice (phenotypes include cerebrovascular amyloid deposition and mild neuronal loss), as well as wildtype mice [112]; the same isoflurane regime was not found to affect cognitive function in 14-16-month-old APP23 mice. In line with this, repeated exposure to 1MAC isoflurane over 4 weeks was not found to impair spatial working and cognition in tri-transgenic AD mice carrying APP, presenilin 1 and tau protein mutations, despite increased phosphorylated-tau expression in the hippocampus [113]. Collectively, the discrepant findings between different $\mathrm{AD}$ models do not constitute convincing evidences to support that GA exposure predisposes/accelerates Alzheimer's disease.

There has been significant research effort to uncover the cellular and molecular mechanisms that could underlie general anesthetics' potential neurotoxic effects on AD brain. Majority of studies focused on anesthetics' ability to induce neuronal apoptosis and to potentiate $\mathrm{AD}$-associated pathology, including defective amyloid protein pathway, tau protein hyperphosphorylation and neuroinflammation.

An early in vitro study on pheochromacytoma cells confirmed that inhalational anesthetics isoflurane and halothane induced dose- and time-dependent Ab42 oligomerization, even at clinically relevant concentrations, and 1-2MAC of isoflurane or halothane significantly potentiated $\mathrm{Ab}$-induced cytotoxicity in pheochromacytoma [114]. Using neuroglioma H4 cells stably transfected with full-length APP, Xie et al. further demonstrated that $2 \%$ isoflurane for $6 \mathrm{~h}$ reduced C-terminal precursor protein while it increased $\mathrm{Ab} 40$ and $\mathrm{Ab} 42$ release, that suggested isoflurane enhanced pathogenic APP cleavage by $\gamma$-secretase. Moreover, isoflurane-induced caspase-3 activation to indicate apoptosis, and such effect could not be attenuated by reducing $\mathrm{Ab}$ in the cellular environment by Ab-neutralizing antibody or $\gamma$-secretase inhibitor; this suggests that isoflurane-induced apoptosis might be independent of $\mathrm{Ab}$ accumulation [115]. The relationship between caspase and amyloid-beta was further explored in vivo, 
wherein $2 \mathrm{~h} 1.4 \%$ of isoflurane increased caspase 3 activation in mouse brain from 6 to $12 \mathrm{~h}$ after exposure, which preceded upregulation of b-site APP-cleaving enzyme (BACE, or $\beta$-secretase) and $\mathrm{Ab}$ at $12-24 \mathrm{~h}$ post-exposure. Isoflurane also downregulated Golgi-associated, gamma adaptin ear-containing, ARF-binding protein 3 (GGA3 ), an enzyme that degrades BACE and is inhibited by active, cleaved caspase 3 . Taken together, such findings may suggest that isoflurane-induced caspase 3 activation could lead to BACE stabilization and promote Ab formation. Conversely, the study also showed that $\mathrm{Ab}$ aggregation inhibitor (iA $\beta 5$ or clioquinol) reduced caspase 3 activation, to suggest reciprocal regulation of this pathway [116, 117]. A similar in vivo study reported that $2 \mathrm{~h}$ $2.5 \%$ sevoflurane exposure also elicited the time-specific events of caspase activation, BACE upregulation and $\mathrm{Ab}$ production. The study also demonstrated that pan-caspase inhibitor Z-VAD reversed sevoflurane-induced Ab synthesis, to strengthen the hypothesis that caspase 3 activation could be upstream of amyloid processing [118]. Nuclear magnetic resonance studies suggested that some anesthetics could directly interact with $\mathrm{Ab}$ to favor oligomerization. Specifically, it was demonstrated that isoflurane and desflurane with their smaller molecular size could interact with critical amino acid residues G29, A30 and I31, which are located within the loop region connecting two $\mathrm{Ab}$ helices, and cause chemical shifts in these residues to promote $\mathrm{Ab}$ oligomerization at clinically relevant concentrations [119]. Propofol with its larger molecular size was not found to interact with said residues and enhance

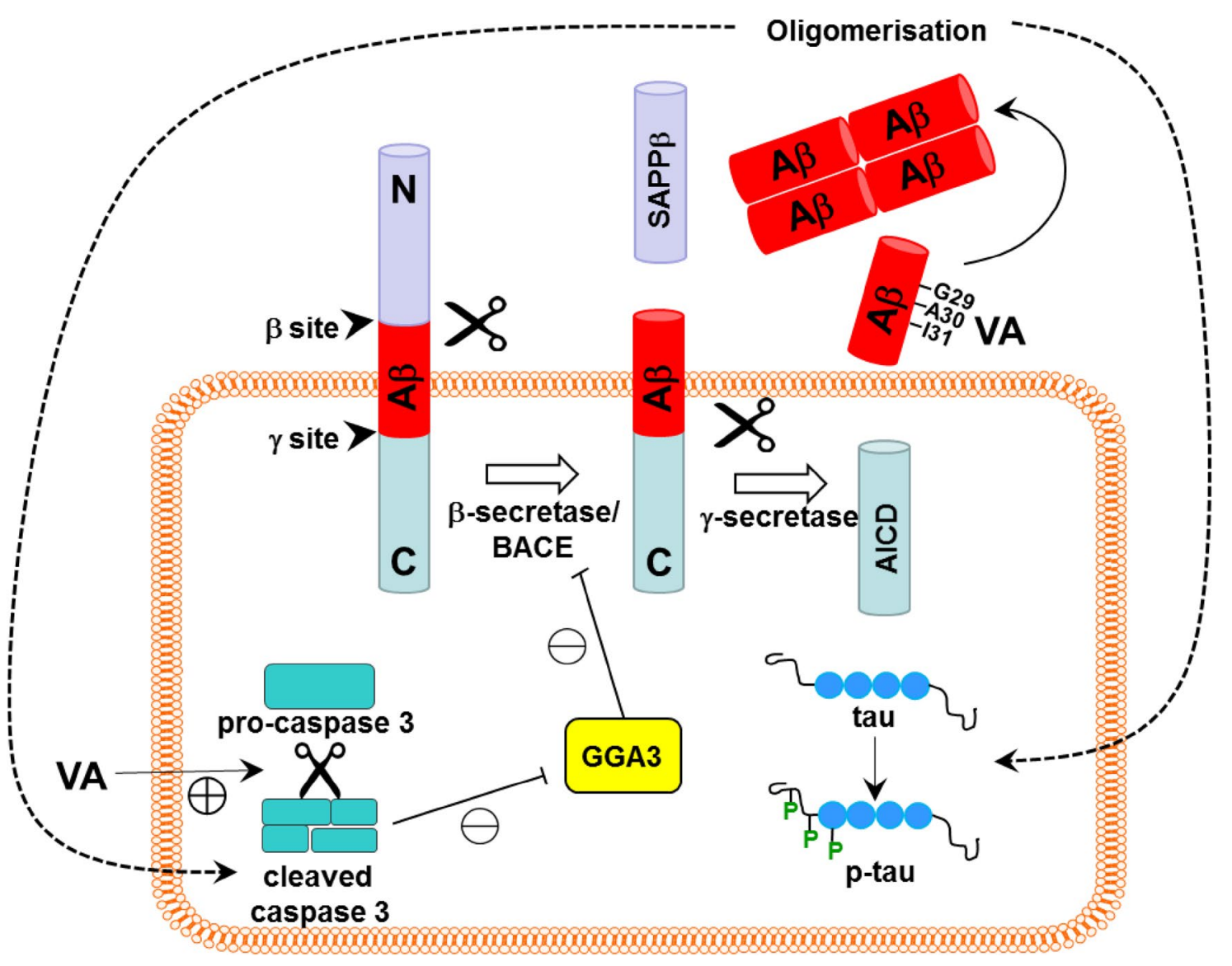

Fig. 4 The hypothesized pathways of volatile anesthetics induced neuropathology associated with Alzheimer's disease. Volatile anesthetic was demonstrated to promote toxic Ab production and aggregation, and such effect was shown to be downstream of VA-induced caspase- 3 cleavage and activation. The cleaved caspase 3 could inactivate Golgi-associated, gamma adaptin ear-containing, ARF-binding protein 3 (GGA3), which degrades b-site APP-cleaving enzyme (BACE, or b-secretase). The overall effect is cellular stabilization of $\mathrm{BACE} / \mathrm{b}$-secretase and increased processing of amyloid progenitor protein (APP) by $\beta$-secretase and $\gamma$-secretase, leading to accumulation of neurotoxic $\mathrm{Ab}$ aggregates. Reciprocal regulation of this pathway may also exist, whereby inhibiting $\mathrm{Ab}$ oligomerization could reduce caspase 3 activation. Caspase 3 activation and $\mathrm{Ab}$ accumulation could also be upstream of tau phosphorylation, as Ab oligomerization inhibitor prevented tau hyper-phosphorylation. In addition, owing to their small molecular size, volatile anesthetics have been shown to directly interact with residues G29, A30 and I31 of Ab to promote Ab oligomerization. $A b$ amyloid-beta protein, $A I C D$ amyloid precursor protein intracellular domain, $B A C E$ b-site amyloid precursor protein cleaving enzyme, GGA3 Golgi-associated, gamma adaptin earcontaining, ARF-binding protein 3, p-tau phosphorylated-tau; sAPPb, soluble amyloid precursor protein $\mathrm{b}, V A$ volatile anesthetics 
oligomerization at clinical concentration, yet a positive observation was made at very high propofol concentration [120] (Fig. 4).

Anesthetics have also been shown to promote tau hyperphosphorylation, another hallmark pathology of Alzheimer's disease. Sevoflurane [121] and propofol [122] were found to induce dose-dependent, transient tau hyperphosphorylation in wildtype mouse brain, with repeated exposure resulting in persistent hippocampal hyperphosphorylation and significant impairment to spatial memory, as assessed by Morris Water Maze test. Anesthetic adjuvant dexmedetomidine also led to reversible tau phosphorylation in WT mouse hippocampus for up to $6 \mathrm{~h}$, yet impairment to spatial memory persisted to 1 week following treatment [123]. In tri-transgenic AD mice harboring APP, presenillin 1 and tau mutations, isoflurane or halothane exposure significantly increased tau phosphorylation in the hippocampal CA1 region, but both anesthetics were not associated with cognitive decline, with halothane even improving memory and learning [113]. In contrast, $\mathrm{Li}$ et al. reported that isoflurane-induced hippocampal tau hyperphosphorylation in APP695 mice was accompanied by decline in spatial memory performance [109]. Isoflurane also increased tau phosphorylation in brain tissues and neuronal culture from APP/PS1 transgenic mice, and tau hyperphosphorylation could be attenuated by caspase inhibitor or $\mathrm{A} \beta$ generation inhibitor, to suggest that caspase activation and $A \beta$ accumulation could be upstream of tau phosphorylation [124] (Fig. 4).

Clinical studies have also observed changes in cerebral spinal fluid levels of $\mathrm{Ab}$ and tau protein in patients following surgery plus general anesthesia. In this regard, CSF total-tau, phosphor-tau, Ab (1-40 or 1-42 form), total$\mathrm{tau} / \mathrm{Ab}$ ratio and phosphor-tau/Ab ratio have been some of the most widely used biomarkers aiding the diagnosis of Alzheimer's disease and dementia, and high specificity and sensitivity can be achieved by combining different biomarkers (e.g., phosphor-tau/Ab ratio plus total tau) $[125,126]$. In patients who have undergone endoscopic nasal surgery, GA with sevoflurane or propofol increased CSF total-tau and phosphorylated-tau181P for $48 \mathrm{~h}$ to a similar extent without altering CSF Ab1-42 level [127]. A randomized study also reported that the threefold increase in CSF tau protein level and tau/Ab ratio is independent of anesthetic type (isoflurane vs. propofol) $24 \mathrm{~h}$ following neurosurgery/otolaryngeal surgery, with minimal effect on CSF Ab level [128]. Moreover, in patients receiving lower extremity or lower abdominal surgery, compared to spinal anesthesia alone, combined anesthesia with isoflurane increased CSF level of Ab40 at $24 \mathrm{~h}$, whereas when combined with desflurane CSF, Ab42 decreased $2 \mathrm{~h}$ after surgery; the three modes of anesthesia did not differ in their effects on CSF tau protein [129]. In conclusion, these preliminary clinical studies partially concur with observations from in vitro and animal studies, however, their relatively small sample size and different surgery/anesthesia protocols limit further interpretation of the findings.

Current clinical evidences on this subject are far from conclusive. A meta-analysis on 15 case-control studies reported that GA exposure, single or cumulative, is not associated with higher risk of AD [130] compared to nosurgery/anesthesia control or regional anesthesia; a prospective cohort study similarly concluded that GA does not significantly increase dementia/AD incidence during a 7-year follow-up [131]. In contrast, a nationwide case-control study reported that subjects receiving surgery and general anesthesia are at higher risk of developing dementia, in particular with multiple surgery/anesthesia challenge, when compared to no-surgery/anesthesia controls [132]. Consistent with such, a cohort study concluded that surgery plus anesthesia is associated with increased incidence of dementia and reduced time interval to dementia diagnosis, regardless of the mode of anesthesia received (general or regional) [133].

\section{Conclusion}

The developing and aging brain may be vulnerable to anesthesia. An important mechanism for anesthesia-induced developmental neurotoxicity is widespread neuroapoptosis, whereby an early exposure to anesthesia causes longlasting impairments in neuronal communication and faulty formation of neuronal circuitries. Exposure to anesthesia to the aged brain can be a risk of the long-lasting impairments of cognitive function. However, the neuroprotective property of general anesthetics in brain injury is also increasingly recognized. That is to say, one should bear in mind the "Ying and Yang" balance of general anesthetics in daily clinical practice. Once this is implemented well, patients will be benefit from "precision" anesthesia. In addition, one should also consider the detrimental effects of trauma induced by surgery on vital organs; in particular, systemic inflammatory responses following surgery can cause various organ injury/dysfunction including cognitive impairment [134]. Therefore, how the perioperative team including anesthetists, surgeons and intensivists should work together in an optimal manner is important for the best benefits of our patients.

Acknowledgements This work was supported by BJA Fellow grant, NIAA, London, UK.

Author contributions All authors contributed to the preparation of the manuscript. LW and HZ designed and created the figures for the manuscript. 


\section{Compliance with ethical standards}

Conflict of interest The authors declare that there is no competing interest.

Open Access This article is distributed under the terms of the Creative Commons Attribution 4.0 International License (http://creativeco mmons.org/licenses/by/4.0/), which permits unrestricted use, distribution, and reproduction in any medium, provided you give appropriate credit to the original author(s) and the source, provide a link to the Creative Commons license, and indicate if changes were made.

\section{References}

1. Wu L, Zhao H, Wang T, Pac-Soo C, Ma D. Cellular signaling pathways and molecular mechanisms involving inhalational anesthetics-induced organoprotection. J Anesth. 2014;28:740-58.

2. Eckenhoff JE. Relationship of anesthesia to postoperative personality changes in children. AMA Am J Dis Child. 1953;86:587-91.

3. Bedford PD. Adverse cerebral effects of anaesthesia on old people. Lancet. 1955;269:259-63.

4. FDA. FDA review results in new warnings about using general anesthetics and sedation drugs in young children and pregnant women, vol. 376. 2016. p. 905-7.

5. Franks NP. Molecular targets underlying general anaesthesia. $\mathrm{Br}$ J Pharmacol. 2006;147(Suppl 1):72-81.

6. Chau PL. New insights into the molecular mechanisms of general anaesthetics. Br J Pharmacol. 2010;161:288-307.

7. Jevtovic-Todorovic V, Hartman RE, Izumi Y, Benshoff ND, Dikranian K, Zorumski C, Olney JW, Wozniak DF. Early exposure to common anesthetic agents causes widespread neurodegeneration in the developing rat brain and persistent learning deficits. J Neurosci. 2003;23:876-82.

8. Stratmann G, Sall JW, May LD, Bell JS, Magnusson KR, Rau V, Visrodia KH, Alvi RS, Ku B, Lee MT, Dai R. Isoflurane differentially affects neurogenesis and long-term neurocognitive function in 60-day-old and 7-day-old rats. Anesthesiology. 2009;110:834-48.

9. Stratmann G, Sall JW, May LD, Loepke AW, Lee MT. Beyond anesthetic properties: the effects of isoflurane on brain cell death, neurogenesis, and long-term neurocognitive function. Anesth Analg. 2010;110:431-7.

10. Yu D, Jiang Y, Gao J, Liu B, Chen P. Repeated exposure to propofol potentiates neuroapoptosis and long-term behavioral deficits in neonatal rats. Neurosci Lett. 2013;534:41-6.

11. Fredriksson A, Ponten E, Gordh T, Eriksson P. Neonatal exposure to a combination of N-methyl-D-aspartate and gammaaminobutyric acid type A receptor anesthetic agents potentiates apoptotic neurodegeneration and persistent behavioral deficits. Anesthesiology. 2007;107:427-36.

12. Fredriksson A, Archer T, Alm H, Gordh T, Eriksson P. Neurofunctional deficits and potentiated apoptosis by neonatal NMDA antagonist administration. Behav Brain Res. 2004;153:367-76.

13. Paule MG, Li M, Allen RR, Liu F, Zou X, Hotchkiss C, Hanig JP, Patterson TA, Slikker W Jr, Wang C. Ketamine anesthesia during the first week of life can cause long-lasting cognitive deficits in rhesus monkeys. Neurotoxicol Teratol. 2011;33:220-30.

14. Raper J, Alvarado MC, Murphy KL, Baxter MG. Multiple anesthetic exposure in infant monkeys alters emotional reactivity to an acute stressor. Anesthesiology. 2015;123:1084-92.
15. Alvarado MC, Murphy KL, Baxter MG. Visual recognition memory is impaired in rhesus monkeys repeatedly exposed to sevoflurane in infancy. Br J Anaesth. 2017;119:517-23.

16. Hofacer RD, Deng M, Ward CG, Joseph B, Hughes EA, Jiang C, Danzer SC, Loepke AW. Cell age-specific vulnerability of neurons to anesthetic toxicity. Ann Neurol. 2013;73:695-704.

17. Wei H, Kang B, Wei W, Liang G, Meng QC, Li Y, Eckenhoff RG. Isoflurane and sevoflurane affect cell survival and BCL-2/BAX ratio differently. Brain Res. 2005;1037:139-47.

18. Shu Y, Patel SM, Pac-Soo C, Fidalgo AR, Wan Y, Maze M, Ma D. Xenon pretreatment attenuates anesthetic-induced apoptosis in the developing brain in comparison with nitrous oxide and hypoxia. Anesthesiology. 2010;113:360-8.

19. Zhang Y, Dong Y, Wu X, Lu Y, Xu Z, Knapp A, Yue Y, Xu $\mathrm{T}$, Xie Z. The mitochondrial pathway of anesthetic isofluraneinduced apoptosis. J Biol Chem. 2010;285:4025-37.

20. Wei H, Liang G, Yang H, Wang Q, Hawkins B, Madesh M, Wang S, Eckenhoff RG. The common inhalational anesthetic isoflurane induces apoptosis via activation of inositol 1,4,5-trisphosphate receptors. Anesthesiology. 2008;108:251-60.

21. Yang H, Liang G, Hawkins BJ, Madesh M, Pierwola A, Wei $\mathrm{H}$. Inhalational anesthetics induce cell damage by disruption of intracellular calcium homeostasis with different potencies. Anesthesiology. 2008;109:243-50.

22. Joseph JD, Peng Y, Mak DO, Cheung KH, Vais H, Foskett $\mathrm{JK}$, Wei H. General anesthetic isoflurane modulates inositol 1,4,5-trisphosphate receptor calcium channel opening. Anesthesiology. 2014;121:528-37.

23. Ren G, Zhou Y, Liang G, Yang B, Yang M, King A, Wei H. General anesthetics regulate autophagy via modulating the inositol 1,4,5-trisphosphate receptor: implications for dual effects of cytoprotection and cytotoxicity. Sci Rep. 2017;7:12378.

24. Wilder RT, Flick RP, Sprung J, Katusic SK, Barbaresi WJ, Mickelson C, Gleich SJ, Schroeder DR, Weaver AL, Warner DO. Early exposure to anesthesia and learning disabilities in a population-based birth cohort. Anesthesiology. 2009; 110:796-804.

25. Flick RP, Katusic SK, Colligan RC, Wilder RT, Voigt RG, Olson MD, Sprung J, Weaver AL, Schroeder DR, Warner DO. Cognitive and behavioral outcomes after early exposure to anesthesia and surgery. Pediatrics. 2011;128:e1053-61.

26. Hansen TG, Pedersen JK, Henneberg SW, Pedersen DA, Murray JC, Morton NS, Christensen K. Academic performance in adolescence after inguinal hernia repair in infancy: a nationwide cohort study. Anesthesiology. 2011;114:1076-85.

27. Ing C, DiMaggio C, Whitehouse A, Hegarty MK, Brady J, von Ungern-Sternberg BS, Davidson A, Wood AJ, Li G, Sun LS. Long-term differences in language and cognitive function after childhood exposure to anesthesia. Pediatrics. 2012;130:e476-85.

28. Davidson AJ, Disma N, de Graaff JC, Withington DE, Dorris L, Bell G, Stargatt R, Bellinger DC, Schuster T, Arnup SJ, Hardy P, Hunt RW, Takagi MJ, Giribaldi G, Hartmann PL, Salvo I, Morton NS, von Ungern Sternberg BS, Locatelli BG, Wilton N, Lynn A, Thomas JJ, Polaner D, Bagshaw O, Szmuk P, Absalom AR, Frawley G, Berde C, Ormond GD, Marmor J, McCann ME, GAS consortium. Neurodevelopmental outcome at 2 years of age after general anaesthesia and awake-regional anaesthesia in infancy (GAS): an international multicentre, randomised controlled trial. Lancet. 2016;387:239-50.

29. Sun LS, Li G, Miller TL, Salorio C, Byrne MW, Bellinger DC, Ing C, Park R, Radcliffe J, Hays SR, DiMaggio CJ, Cooper TJ, Rauh V, Maxwell LG, Youn A, McGowan FX. Association between a single general anesthesia exposure before age 36 months and neurocognitive outcomes in later childhood. JAMA. 2016;315:2312-20. 
30. DiMaggio C, Sun LS, Kakavouli A, Byrne MW, Li G. A retrospective cohort study of the association of anesthesia and hernia repair surgery with behavioral and developmental disorders in young children. J Neurosurg Anesthesiol. 2009;21:286-91.

31. DiMaggio C, Sun LS, Li G. Early childhood exposure to anesthesia and risk of developmental and behavioral disorders in a sibling birth cohort. Anesth Analg. 2011;113:1143-51.

32. Gluckman PD, Pinal CS, Gunn AJ. Hypoxic-ischemic brain injury in the newborn: pathophysiology and potential strategies for intervention. Semin Neonatol. 2001;6:109-20.

33. Huang BY, Castillo M. Hypoxic-ischemic brain injury: imaging findings from birth to adulthood. Radiographics 2008; 28:417-39 (quiz 617).

34. Black RE, Cousens S, Johnson HL, Lawn JE, Rudan I, Bassani DG, Jha P, Campbell H, Walker CF, Cibulskis R, Eisele T, Liu L, Mathers C, Child Health Epidemiology Reference Group of WHO and UNICEF. Global, regional, and national causes of child mortality in 2008: a systematic analysis. Lancet. 2010;375:1969-87.

35. Geocadin RG, Koenig MA, Jia X, Stevens RD, Peberdy MA. Management of brain injury after resuscitation from cardiac arrest. Neurol Clin. 2008;26:487-506. ix.

36. Shalak L, Perlman JM. Hypoxic-ischemic brain injury in the term infant-current concepts. Early Hum Dev. 2004;80:125-41.

37. Aragones J, Schneider M, Van Geyte K, Fraisl P, Dresselaers T, Mazzone M, Dirkx R, Zacchigna S, Lemieux H, Jeoung NH, Lambrechts D, Bishop T, Lafuste P, Diez-Juan A, Harten SK, Van Noten P, De Bock K, Willam C, Tjwa M, Grosfeld A, Navet R, Moons L, Vandendriessche T, Deroose C, Wijeyekoon B, Nuyts J, Jordan B, Silasi-Mansat R, Lupu F, Dewerchin M, Pugh C, Salmon P, Mortelmans L, Gallez B, Gorus F, Buyse J, Sluse F, Harris RA, Gnaiger E, Hespel P, Van Hecke P, Schuit F, Van Veldhoven P, Ratcliffe P, Baes M, Maxwell P, Carmeliet P. Deficiency or inhibition of oxygen sensor Phd1 induces hypoxia tolerance by reprogramming basal metabolism. Nat Genet. 2008;40:170-80.

38. Eltzschig HK, Eckle T. Ischemia and reperfusion-from mechanism to translation. Nat Med. 2011;17:1391-401.

39. Kim MJ, Hur J, Ham IH, Yang HJ, Kim Y, Park S, Cho YW. Expression and activity of the na-k ATPase in ischemic injury of primary cultured astrocytes. Korean J Physiol Pharmacol. 2013;17:275-81.

40. Williams CE, Gunn A, Gluckman PD. Time course of intracellular edema and epileptiform activity following prenatal cerebral ischemia in sheep. Stroke. 1991;22:516-21.

41. Williams CE, Gunn AJ, Mallard C, Gluckman PD. Outcome after ischemia in the developing sheep brain: an electroencephalographic and histological study. Ann Neurol. 1992;31:14-21.

42. Beilharz EJ, Williams CE, Dragunow M, Sirimanne ES, Gluckman PD. Mechanisms of delayed cell death following hypoxic-ischemic injury in the immature rat: evidence for apoptosis during selective neuronal loss. Brain Res Mol Brain Res. 1995;29:1-14.

43. Xu M, Zhang HL. Death and survival of neuronal and astrocytic cells in ischemic brain injury: a role of autophagy. Acta Pharmacol Sin. 2011;32:1089-99.

44. Tian J, Cheng J, Zhang J, Ye L, Zhang F, Dong Q, Wang H, Fu F. Protection of pyruvate against glutamate excitotoxicity is mediated by regulating DAPK1 protein complex. PLoS One. 2014;9:e95777.

45. Siesjo BK, Bengtsson F. Calcium fluxes, calcium antagonists, and calcium-related pathology in brain ischemia, hypoglycemia, and spreading depression: a unifying hypothesis. J Cereb Blood Flow Metab. 1989;9:127-40.
46. Harada H, Kelly PJ, Cole DJ, Drummond JC, Patel PM. Isoflurane reduces $\mathrm{N}$-methyl-D-aspartate toxicity in vivo in the rat cerebral cortex. Anesth Analg. 1999;89:1442-7.

47. Kimbro JR, Kelly PJ, Drummond JC, Cole DJ, Patel PM. Isoflurane and pentobarbital reduce AMPA toxicity in vivo in the rat cerebral cortex. Anesthesiology. 2000;92:806-12.

48. Kudo M, Aono M, Lee Y, Massey G, Pearlstein RD, Warner DS. Effects of volatile anesthetics on $N$-methyl-D-aspartate excitotoxicity in primary rat neuronal-glial cultures. Anesthesiology. 2001;95:756-65.

49. Bickler PE, Warner DS, Stratmann G, Schuyler JA. gammaAminobutyric acid-A receptors contribute to isoflurane neuroprotection in organotypic hippocampal cultures. Anesth Analg. 2003;97:564-71 (table of contents).

50. Elsersy H, Mixco J, Sheng H, Pearlstein RD, Warner DS. Selective gamma-aminobutyric acid type A receptor antagonism reverses isoflurane ischemic neuroprotection. Anesthesiology. 2006;105:81-90.

51. Franks JJ, Horn JL, Janicki PK, Singh G. Halothane, isoflurane, xenon, and nitrous oxide inhibit calcium ATPase pump activity in rat brain synaptic plasma membranes. Anesthesiology. 1995;82:108-17.

52. Franks NP, Dickinson R, de Sousa SL, Hall AC, Lieb WR. How does xenon produce anaesthesia? Nature. 1998;396:324.

53. de Sousa SL, Dickinson R, Lieb WR, Franks NP. Contrasting synaptic actions of the inhalational general anesthetics isoflurane and xenon. Anesthesiology. 2000;92:1055-66.

54. Dickinson R, Peterson BK, Banks P, Simillis C, Martin JC, Valenzuela CA, Maze M, Franks NP. Competitive inhibition at the glycine site of the N-methyl-D-aspartate receptor by the anesthetics xenon and isoflurane: evidence from molecular modeling and electrophysiology. Anesthesiology. 2007;107:756-67.

55. Lachmann B, Armbruster S, Schairer W, Landstra M, Trouwborst A, Van Daal GJ, Kusuma A, Erdmann W. Safety and efficacy of xenon in routine use as an inhalational anaesthetic. Lancet. 1990;335:1413-5.

56. Goto T, Suwa K, Uezono S, Ichinose F, Uchiyama M, Morita S. The blood-gas partition coefficient of xenon may be lower than generally accepted. Br J Anaesth. 1998;80:255-6.

57. Lynch C 3rd, Baum J, Tenbrinck R. Xenon anesthesia. Anesthesiology. 2000;92:865-8.

58. Dingley J, Ivanova-Stoilova TM, Grundler S, Wall T. Xenon: recent developments. Anaesthesia. 1999;54:335-46.

59. Ma D, Wilhelm S, Maze M, Franks NP. Neuroprotective and neurotoxic properties of the 'inert' gas, xenon. Br J Anaesth. 2002;89:739-46.

60. Ma D, Hossain M, Pettet GK, Luo Y, Lim T, Akimov S, Sanders RD, Franks NP, Maze M. Xenon preconditioning reduces brain damage from neonatal asphyxia in rats. J Cereb Blood Flow Metab. 2006;26:199-208.

61. Ma D, Hossain M, Chow A, Arshad M, Battson RM, Sanders RD, Mehmet H, Edwards AD, Franks NP, Maze M. Xenon and hypothermia combine to provide neuroprotection from neonatal asphyxia. Ann Neurol. 2005;58:182-93.

62. Dingley J, Tooley J, Porter H, Thoresen M. Xenon provides short-term neuroprotection in neonatal rats when administered after hypoxia-ischemia. Stroke. 2006;37:501-6.

63. Faulkner S, Bainbridge A, Kato T, Chandrasekaran M, Kapetanakis AB, Hristova M, Liu M, Evans S, De Vita E, Kelen D, Sanders RD, Edwards AD, Maze M, Cady EB, Raivich G, Robertson NJ. Xenon attenuates cerebral damage after ischemia in pigs. Anesthesiology. 2005;102:929-36.

64. Faulkner S, Bainbridge A, Kato T. Xenon augmented hypothermia reduces early lactate/ $\mathrm{N}$-acetylaspartate and cell death in perinatal asphyxia. Ann Neurol. 2011;70:133-50. 
65. Mayor S. Xenon shows promise to prevent brain injury from lack of oxygen in newborns. BMJ. 2010;340:c2005.

66. Sharp FR, Ran R, Lu A, Tang Y, Strauss KI, Glass T, Ardizzone $\mathrm{T}$, Bernaudin $\mathrm{M}$. Hypoxic preconditioning protects against ischemic brain injury. NeuroRx. 2004;1:26-35.

67. Semenza GL. Life with oxygen. Science. 2007;318:62-4.

68. Zhu LL, Wu LY, Yew DT, Fan M. Effects of hypoxia on the proliferation and differentiation of NSCs. Mol Neurobiol. 2005;31:231-42.

69. Hill P, Shukla D, Tran MG, Aragones J, Cook HT, Carmeliet P, Maxwell PH. Inhibition of hypoxia inducible factor hydroxylases protects against renal ischemia-reperfusion injury. J Am Soc Nephrol. 2008;19:39-46.

70. Huang YF, Yang CH, Huang CC, Tai MH, Hsu KS. Pharmacological and genetic accumulation of hypoxia-inducible factor1alpha enhances excitatory synaptic transmission in hippocampal neurons through the production of vascular endothelial growth factor. J Neurosci. 2010;30:6080-93.

71. Itoh T, Namba T, Fukuda K, Semenza GL, Hirota K. Reversible inhibition of hypoxia-inducible factor 1 activation by exposure of hypoxic cells to the volatile anesthetic halothane. FEBS Lett. 2001;509:225-9.

72. Zhao HIM, Yang JL, Savage S, Ma DQ. Hypoxia-inducible factor-1: a possible link between inhalational anesthetics and tumor progression? Acta Anaesthesiol Taiwan. 2014;52:70-6.

73. Zhao H, Watts HR, Chong M, Huang H, Tralau-Stewart C, Maxwell PH, Maze M, George AJ, Ma D. Xenon treatment protects against cold ischemia associated delayed graft function and prolongs graft survival in rats. Am J Transpl. 2013;13:2006-18.

74. Ma D, Lim T, Xu J, Tang H, Wan Y, Zhao H, Hossain M, Maxwell $\mathrm{PH}$, Maze $\mathrm{M}$. Xenon preconditioning protects against renal ischemic-reperfusion injury via HIF-1alpha activation. J Am Soc Nephrol. 2009;20:713-20.

75. Raphael J, Zuo Z, Abedat S, Beeri R, Gozal Y. Isoflurane preconditioning decreases myocardial infarction in rabbits via upregulation of hypoxia inducible factor 1 that is mediated by mammalian target of rapamycin. Anesthesiology. 2008;108:415-25.

76. Li QF, Zhu YS, Jiang H. Isoflurane preconditioning activates HIF-1alpha, iNOS and Erk1/2 and protects against oxygen-glucose deprivation neuronal injury. Brain Res. 2008;1245:26-35.

77. Limatola V, Ward P, Cattano D, Gu J, Giunta F, Maze M, Ma D. Xenon preconditioning confers neuroprotection regardless of gender in a mouse model of transient middle cerebral artery occlusion. Neuroscience. 2010;165:874-81.

78. Robinson TN, Raeburn CD, Tran ZV, Angles EM, Brenner LA, Moss M. Postoperative delirium in the elderly: risk factors and outcomes. Ann Surg. 2009;249:173-8.

79. Moller JT, Cluitmans P, Rasmussen LS, Houx P, Rasmussen H, Canet J, Rabbitt P, Jolles J, Larsen K, Hanning CD, Langeron O, Johnson T, Lauven PM, Kristensen PA, Biedler A, van Beem H, Fraidakis O, Silverstein JH, Beneken JE, Gravenstein JS. Longterm postoperative cognitive dysfunction in the elderly ISPOCD1 study. ISPOCD investigators. International Study of Post-Operative Cognitive Dysfunction. Lancet. 1998;351:857-61.

80. Dokkedal U, Hansen TG, Rasmussen LS, Mengel-From J, Christensen K. Cognitive functioning after surgery in middle-aged and elderly Danish twins. Anesthesiology. 2016;124:312-21.

81. Abildstrom H, Rasmussen LS, Rentowl P, Hanning CD, Rasmussen H, Kristensen PA, Moller JT. Cognitive dysfunction 1-2 years after non-cardiac surgery in the elderly. ISPOCD group. International Study of Post-Operative Cognitive Dysfunction. Acta Anaesthesiol Scand. 2000;44:1246-51.

82. Patel D, Lunn AD, Smith AD, Lehmann DJ, Dorrington KL. Cognitive decline in the elderly after surgery and anaesthesia: results from the Oxford Project to Investigate Memory and Ageing (OPTIMA) cohort. Anaesthesia. 2016;71:1144-52.

83. Inouye SK, Westendorp RG, Saczynski JS. Delirium in elderly people. Lancet. 2014;383:911-22.

84. Bilotta F, Qeva E, Matot I. Anesthesia and cognitive disorders: a systematic review of the clinical evidence. Expert Rev Neurother. 2016;16:1311-20.

85. Rasmussen LS, Johnson T, Kuipers HM, Kristensen D, Siersma VD, Vila P, Jolles J, Papaioannou A, Abildstrom H, Silverstein JH, Bonal JA, Raeder J, Nielsen IK, Korttila K, Munoz L, Dodds C, Hanning CD, Moller JT, ISPOCD2(International Study of PostoperativeCognitive Dysfunction) Investigators. Does anaesthesia cause postoperative cognitive dysfunction? A randomised study of regional versus general anaesthesia in 438 elderly patients. Acta Anaesthesiol Scand. 2003;47:260-6.

86. Bryson GL, Wyand A. Evidence-based clinical update: general anesthesia and the risk of delirium and postoperative cognitive dysfunction. Can J Anaesth. 2006;53:669-77.

87. Evered L, Scott DA, Silbert B, Maruff P. Postoperative cognitive dysfunction is independent of type of surgery and anesthetic. Anesth Analg. 2011;112:1179-85.

88. Radtke FM, Franck M, Lendner J, Kruger S, Wernecke KD, Spies CD. Monitoring depth of anaesthesia in a randomized trial decreases the rate of postoperative delirium but not postoperative cognitive dysfunction. Br J Anaesth. 2013;110(Suppl 1):i98-105.

89. Farag E, Chelune GJ, Schubert A, Mascha EJ. Is depth of anesthesia, as assessed by the Bispectral Index, related to postoperative cognitive dysfunction and recovery? Anesth Analg. 2006;103:633-40.

90. Sprung J, Roberts RO, Knopman DS, Price LL, Schulz HP, Tatsuyama CL, Weingarten TN, Schroeder DR, Hanson AC, Petersen RC, Warner DO. Mild cognitive impairment and exposure to general anesthesia for surgeries and procedures: a population-based case-control study. Anesth Analg. 2017;124:1277-90.

91. Schoen J, Husemann L, Tiemeyer C, Lueloh A, Sedemund-Adib B, Berger KU, Hueppe M, Heringlake M. Cognitive function after sevoflurane- vs propofol-based anaesthesia for on-pump cardiac surgery: a randomized controlled trial. Br J Anaesth. 2011;106:840-50.

92. Culley DJ, Baxter MG, Yukhananov R, Crosby G. Long-term impairment of acquisition of a spatial memory task following isoflurane-nitrous oxide anesthesia in rats. Anesthesiology. 2004;100:309-14.

93. Callaway JK, Jones NC, Royse AG, Royse CF. Memory impairment in rats after desflurane anesthesia is age and dose dependent. J Alzheimers Dis. 2015;44:995-1005.

94. Stratmann G, Sall JW, Bell JS, Alvi RS, May Ld, Ku B, Dowlatshahi M, Dai R, Bickler PE, Russell I, Lee MT, Hrubos MW, Chiu C. Isoflurane does not affect brain cell death, hippocampal neurogenesis, or long-term neurocognitive outcome in aged rats. Anesthesiology. 2010;112:305-15.

95. Callaway JK, Jones NC, Royse AG, Royse CF. Sevoflurane anesthesia does not impair acquisition learning or memory in the Morris water maze in young adult and aged rats. Anesthesiology. 2012;117:1091-101.

96. Lee IH, Culley DJ, Baxter MG, Xie Z, Tanzi RE, Crosby G. Spatial memory is intact in aged rats after propofol anesthesia. Anesth Analg. 2008;107:1211-5.

97. Zhang Y, Shan GJ, Zhang YX, Cao SJ, Zhu SN, Li HJ, Ma D, Wang DX, First Study of Perioperative Organ Protection (SPOP1) investigators. Propofol compared with sevoflurane general anaesthesia is associated with decreased delayed neurocognitive recovery in older adults. Br J Anaesth. 2018;121:595-604. 
98. Correa-Sales C, Rabin BC, Maze M. A hypnotic response to dexmedetomidine, an alpha 2 agonist, is mediated in the locus coeruleus in rats. Anesthesiology. 1992;76:948-52.

99. Nelson LE, Lu J, Guo T, Saper CB, Franks NP, Maze M. The alpha2-adrenoceptor agonist dexmedetomidine converges on an endogenous sleep-promoting pathway to exert its sedative effects. Anesthesiology. 2003;98:428-36.

100. Sanders RD, Xu J, Shu Y, Januszewski A, Halder S, Fidalgo A, Sun P, Hossain M, Ma D, Maze M. Dexmedetomidine attenuates isoflurane-induced neurocognitive impairment in neonatal rats. Anesthesiology. 2009;110:1077-85.

101. Qiao H, Sanders RD, Ma D, Wu X, Maze M. Sedation improves early outcome in severely septic Sprague Dawley rats. Crit Care. 2009;13:R136.

102. Su X, Meng ZT, Wu XH, Cui F, Li HL, Wang DX, Zhu X, Zhu $\mathrm{SN}$, Maze M, Ma D. Dexmedetomidine for prevention of delirium in elderly patients after non-cardiac surgery: a randomised, double-blind, placebo-controlled trial. Lancet. 2016;388:1893-902.

103. Zhang DF, Su X, Meng ZT, Li HL, Wang DX, Li XY, Maze $\mathrm{M}, \mathrm{Ma} \mathrm{D}$. Impact of dexmedetomidine on long-term outcomes after noncardiac surgery in elderly: 3-year follow-up of a randomized controlled trial. Ann Surg. 2018. https://doi.org/10.1097/ SLA.0000000000002801 (Epub ahead of print)

104. Wu XH, Cui F, Zhang C, Cui F, Li HL, Wang DX, Zhu X, Zhu SN, Maze M, Ma D. Low-dose dexmedetomidine improves sleep quality pattern in elderly patients after noncardiac surgery in the intensive care unit: a pilot randomized controlled trial. Anesthesiology. 2016;125:979-91.

105. Deiner S, Luo X, Lin HM, Sessler DI, Saager L, Sieber FE, Lee $\mathrm{HB}$, Sano M, and the Dexlirium Writing Group, Jankowski C, Bergese SD, Candiotti K, Flaherty JH, Arora H, Shander A, Rock $\mathrm{P}$. Intraoperative infusion of dexmedetomidine for prevention of postoperative delirium and cognitive dysfunction in elderly patients undergoing major elective noncardiac surgery: a randomized clinical trial. JAMA Surg. 2017;152:e171505.

106. Elder GA, Gama Sosa MA, De Gasperi R. Transgenic mouse models of Alzheimer's disease. Mt Sinai J Med. 2010;77:69-81.

107. Bianchi SL, Tran T, Liu C, Lin S, Li Y, Keller JM, Eckenhoff RG, Eckenhoff MF. Brain and behavior changes in 12-month-old $\mathrm{Tg} 2576$ and nontransgenic mice exposed to anesthetics. Neurobiol Aging. 2008;29:1002-10.

108. Perucho J, Rubio I, Casarejos MJ, Gomez A, Rodriguez-Navarro JA, Solano RM, De Yébenes JG, Mena MA. Anesthesia with isoflurane increases amyloid pathology in mice models of Alzheimer's disease. J Alzheimers Dis. 2010;19:1245-57.

109. Li C, Liu S, Xing Y, Tao F. The role of hippocampal tau protein phosphorylation in isoflurane-induced cognitive dysfunction in transgenic APP695 mice. Anesth Analg. 2014;119:413-9.

110. Miao H, Dong Y, Zhang Y, Zheng H, Shen Y, Crosby G, Culley DJ, Marcantonio ER, Xie Z. Anesthetic isoflurane or desflurane plus surgery differently affects cognitive function in Alzheimer's disease transgenic mice. Mol Neurobiol. 2018;55:5623-38.

111. Zhang C, Zhang Y, Shen Y, Zhao G, Xie Z, Dong Y. Anesthesia/surgery induces cognitive impairment in female Alzheimer's disease transgenic mice. J Alzheimers Dis. 2017;57:505-18.

112. Eckel B, Ohl F, Starker L, Rammes G, Bogdanski R, Kochs E, Blobner M. Effects of isoflurane-induced anaesthesia on cognitive performance in a mouse model of Alzheimer's disease: a randomised trial in transgenic APP23 mice. Eur J Anaesthesiol. 2013;30:605-11.

113. Tang JX, Mardini F, Caltagarone BM, Garrity ST, Li RQ, Bianchi SL, Gomes O, Laferla FM, Eckenhoff RG, Eckenhoff MF. Anesthesia in presymptomatic Alzheimer's disease: a study using the triple-transgenic mouse model. Alzheimers Dement. 2011;7:521-31.e1.
114. Eckenhoff RG, Johansson JS, Wei H, Carnini A, Kang B, Wei W, Pidikiti R, Keller JM, Eckenhoff MF. Inhaled anesthetic enhancement of amyloid-beta oligomerization and cytotoxicity. Anesthesiology. 2004;101:703-9.

115. Xie Z, Dong Y, Maeda U, Alfille P, Culley DJ, Crosby G, Tanzi RE. The common inhalation anesthetic isoflurane induces apoptosis and increases amyloid beta protein levels. Anesthesiology. 2006;104:988-94.

116. Xie Z, Culley DJ, Dong Y, Zhang G, Zhang B, Moir RD, Frosch MP, Crosby G, Tanzi RE. The common inhalation anesthetic isoflurane induces caspase activation and increases amyloid betaprotein level in vivo. Ann Neurol. 2008;64:618-27.

117. Xie Z, Dong Y, Maeda U. The inhalation anesthetic isoflurane induces a vicious cycle of apoptosis and amyloid beta-protein accumulation. J Neurosci. 2007;27:1247-54.

118. Dong Y, Zhang G, Zhang B, Moir RD, Xia W, Marcantonio ER, Culley DJ, Crosby G, Tanzi RE, Xie Z. The common inhalational anesthetic sevoflurane induces apoptosis and increases beta-amyloid protein levels. Arch Neurol. 2009;66:620-31.

119. Mandal PK, Ahuja M. Comprehensive nuclear magnetic resonance studies on interactions of amyloid-beta with different molecular sized anesthetics. J Alzheimers Dis. 2010;22(Suppl 3):27-34

120. Mandal PK, Fodale V. Smaller molecular-sized anaesthetics oligomerize Abeta peptide simulating Alzheimer's disease: a relevant issue. Eur J Anaesthesiol. 2009;26:805-6.

121. Le Freche H, Brouillette J, Fernandez-Gomez FJ, Patin P, Caillierez R, Zommer N, Sergeant N, Buée-Scherrer V, Lebuffe G, Blum D, Buée L. Tau phosphorylation and sevoflurane anesthesia: an association to postoperative cognitive impairment. Anesthesiology. 2012;116:779-87.

122. Whittington RA, Virag L, Marcouiller F, Papon MA, El Khoury NB, Julien C, Morin F, Emala CW, Planel E. Propofol directly increases tau phosphorylation. PLoS One. 2011;6:e16648.

123. Whittington RA, Virag L, Gratuze M, Petry FR, Noël A, Poitras I, Truchetti G, Marcouiller F, Papon MA, El Khoury N, Wong K, Bretteville A, Morin F, Planel E. Dexmedetomidine increases tau phosphorylation under normothermic conditions in vivo and in vitro. Neurobiol Aging. 2015;36:2414-28.

124. Dong Y, Wu X, Xu Z, Zhang Y, Xie Z. Anesthetic isoflurane increases phosphorylated tau levels mediated by caspase activation and Abeta generation. PLoS One. 2012;7:e39386.

125. Ritchie C, Smailagic N, Noel-Storr AH, Ukoumunne O, Ladds EC, Martin S. CSF tau and the CSF tau/ABeta ratio for the diagnosis of Alzheimer's disease dementia and other dementias in people with mild cognitive impairment (MCI). Cochrane Database Syst Rev. 2017;3:CD010803.

126. Shaw LM, Korecka M, Clark CM, Lee VM, Trojanowski JQ. Biomarkers of neurodegeneration for diagnosis and monitoring therapeutics. Nat Rev Drug Discov. 2007;6:295-303.

127. Tang JX, Baranov D, Hammond M, Shaw LM, Eckenhoff MF, Eckenhoff RG. Human Alzheimer and inflammation biomarkers after anesthesia and surgery. Anesthesiology. 2011;115:727-32.

128. Berger M, Nadler JW, Friedman A, McDonagh DL, Bennett ER, Cooter M, Qi W, Laskowitz DT, Ponnusamy V, Newman MF, Shaw LM, Warner DS, Mathew JP, James ML, MAD-PIA trial team. The effect of propofol versus isoflurane anesthesia on human cerebrospinal fluid markers of Alzheimer's disease: results of a randomized trial. J Alzheimers Dis. 2016;52:1299-310.

129. Zhang B, Tian M, Zheng H, Zhen Y, Yue Y, Li T, Li S, Marcantonio ER, Xie Z. Effects of anesthetic isoflurane and desflurane on human cerebrospinal fluid Abeta and tau level. Anesthesiology. 2013;119:52-60. 
130. Seitz DP, Shah PS, Herrmann N, Beyene J, Siddiqui N. Exposure to general anesthesia and risk of Alzheimer's disease: a systematic review and meta-analysis. BMC Geriatr. 2011;11:83.

131. Aiello Bowles EJ, Larson EB, Pong RP, Walker RL, Anderson ML, Yu O, Gray SL, Crane PK, Dublin S. Anesthesia exposure and risk of dementia and alzheimer's disease: a prospective study. J Am Geriatr Soc. 2016;64:602-7.

132. Chen CW, Lin CC, Chen KB, Kuo YC, Li CY, Chung CJ. Increased risk of dementia in people with previous exposure to general anesthesia: a nationwide population-based case-control study. Alzheimers Dement. 2014;10:196-204.

133. Chen PL, Yang CW, Tseng YK, Sun WZ, Wang JL, Wang SJ, Oyang YJ, Fuh JL. Risk of dementia after anaesthesia and surgery. Br J Psychiatry. 2014;204:188-93.
134. Alam A, Hana Z, Jin Z, Suen KC, Ma D. Surgery, neuroinflammation and cognitive impairment. EBioMedicine. 2018;37:547-56.

Publisher's Note Springer Nature remains neutral with regard to jurisdictional claims in published maps and institutional affiliations. 